\title{
EFFECT OF Mini-ThiXoforming PARAMETERS ON MiCROSTRUCTURAL EVOLUTION IN LOW-AlLOY STEEL
}

\author{
Kateřina Rubešová, Hana Jirková, Bohuslav Mašek, Ivan Vorel \\ University of West Bohemia, Univerzitni 22, 30614 Plzeň, Czech Republic
}

\begin{abstract}
The ever increasing demands on the complexity of product shapes and the required material properties drive the development of new technologies. One of these technologies is mini-thixoforming. Thanks to the specific process conditions, near-net-shape products can be made in a single forming step. However, as the process is technically demanding, the use of medium and low-alloy steels has not been explored yet. In the present experiment, the 30MnVS6 low-alloy steel was used. In its initial condition, it has a ferritic-pearlitic microstructure. The initial set of parameters of processing was proposed on the basis of calculation. These parameters were then optimised experimentally. The microstructure of the products consisted of martensite. Consequently, the feasibility of producing bainitic microstructure which offers higher toughness was explored. Controlled cooling was chosen as the technique to obtain bainite. The controlled-cooling process simulated forming in a pre-heated die.
\end{abstract}

Keyword: Thixoforming Mini-thixoforming; Semi-solid processing; 30MnVS6; rapid solidification; low alloy steel
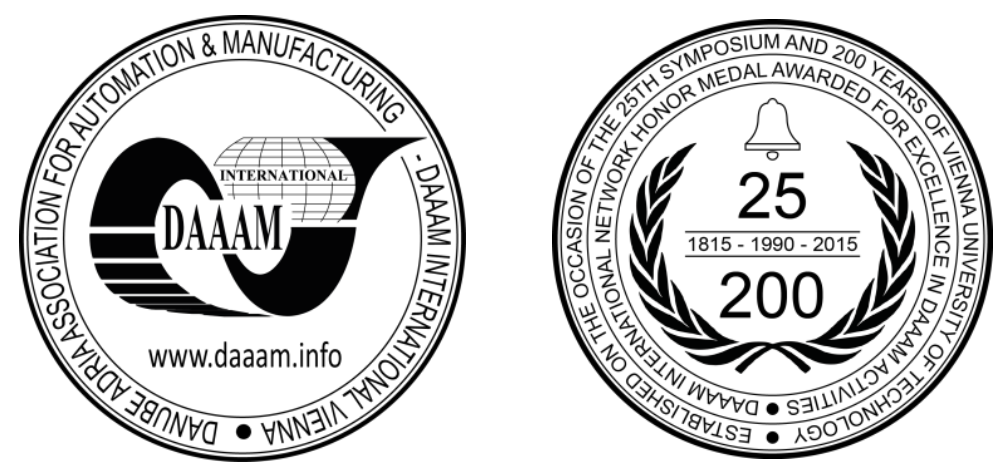

This Publication has to be referred as: Rubesova, K[aterina]; Jirkova, H[ana]; Masek, B[ohuslav] \& Vorel, I[van] (2016). Effect of Mini-Thixoforming Parameters on Microstructural Evolution in Low-Alloy Steel, Proceedings of the 26th DAAAM International Symposium, pp.0803-0809, B. Katalinic (Ed.), Published by DAAAM International, ISBN 978-3-902734-07-5, ISSN 1726-9679, Vienna, Austria DOI: $10.2507 / 26$ th.daaam.proceedings. 112 


\section{Introduction}

Although the principle of thixoforming has been known since the early 1970s, the process is still seen as one of unconventional metal processing methods. It relies on the so-called thixotropic behaviour of materials which occurs after they have been heated to the semi-solid region, i.e. the region between their solidus and liquidus temperatures. Shear forces which act on the partially melted material during the forming process cause a drop in its viscosity. This effect is known as thixotropy [1]. The liquid fraction in the workpiece being formed is between 10 and $60 \%$ [2]. This technique was initially developed primarily for low-melting materials: aluminium, magnesium and tin alloys [3]. Thanks to intensive research in this field, commercial machines for thixoforming of low-melting alloys are already (though scarcely) in use. However, when it comes to steels, the research progress is lagging behind due to technological complexity. Nevertheless, difficult-to-form materials can be processed using a single forming step by using semi-solid forming. In addition, more complex and intricate shapes can be produced than with conventional forming techniques. In addition, unconventional microstructures can be produced even in ordinary materials. [2].

The research into steel processing, in contrast to low-melting alloys, has made less progress, as it encountered substantial technological complexity. The main difficulties related to high processing temperatures, narrow temperature intervals and the resulting need for strict control of the temperature field. In literature, the only detailed description that has been available so far related to high-alloy steels. Up to now, no comprehensive research into the behaviour of lowalloy medium and low-carbon steels has been undertaken. Therefore, this is the field the present experiment focused on. Its objective was to explore the capabilities of mini-thixoforming of microalloyed steel and obtain the desired type of microstructure [4, 5]. Mini-thixoforming enables near-net-shape products to be obtained which are geometrically accurate and require minimum subsequent finishing operations as opposed to those that are normally needed with conventional forming methods for the required accuracy and surface finish. This leads to the material, energy and, consequently, financial savings [6].

\section{Experimental programme}

The material chosen for the experiment was medium-carbon microalloyed 30MnVS6 steel (Tab.1). It is frequently used in forging industry for its good hot formability, good mechanical properties and a low price [7]. However, given it's relatively low carbon and alloy levels, determining the appropriate forming interval may be expected to be very difficult.

\begin{tabular}{lllllllllllll}
\hline $\mathrm{C}$ & $\mathrm{Mn}$ & $\mathrm{Si}$ & $\mathrm{P}$ & $\mathrm{S}$ & $\mathrm{Cu}$ & $\mathrm{Cr}$ & $\mathrm{Ni}$ & $\mathrm{Al}$ & $\mathrm{N}$ & $\mathrm{Mo}$ & $\mathrm{V}$ & $\mathrm{Ti}$ \\
\hline 0.31 & 1.50 & 0.62 & 0.018 & 0.024 & 0.03 & 0.20 & 0.02 & 0.02 & 0.0122 & 0.007 & 0.098 & 0.0261 \\
\hline
\end{tabular}

Table 1. Chemical composition of 30MnVS6 steel, as determined by chemical analysis

In order to determine suitable thixoforming parameters, one needs to know the physical and chemical properties of the material and their profiles throughout the heating process. One of the key characteristics relevant to semi-solid processing is the material's freezing range. The recommended interval for mini-thixoforming is $10-30 \%$, 9]. Since finding these characteristics experimentally is time-consuming, they have been calculated for the present study using JMatPro software and the material's chemical composition data [10]. Fig. 1 shows that this steel begins to melt at $1424{ }^{\circ} \mathrm{C}$ and the melting ends at $1491{ }^{\circ} \mathrm{C}$. Hence, the freezing range is approximately $67{ }^{\circ} \mathrm{C}$. However, the temperature range, in which forming can be carried out is $1440-1476{ }^{\circ} \mathrm{C}$. Together with the high temperature involved, the process window as narrow as this represents a great hurdle to be overcome. The advantage of this material lies in the fact that its melting curve is smooth without any major kinks, which is favourable for temperature control.

The experimental programme was carried out using a thermomechanical simulator. This machine is provided with a special electrical resistance-induction heating system with a feedback control loop for high-accuracy control of the temperature field $[11,12]$. It also incorporates a programmable cooling system for cooling rate control. Specimens with threaded ends for direct clamping in the simulator jaws have been used. The gauge length and diameter of the specimens were 16 and $8 \mathrm{~mm}$, respectively. 
Physical properties

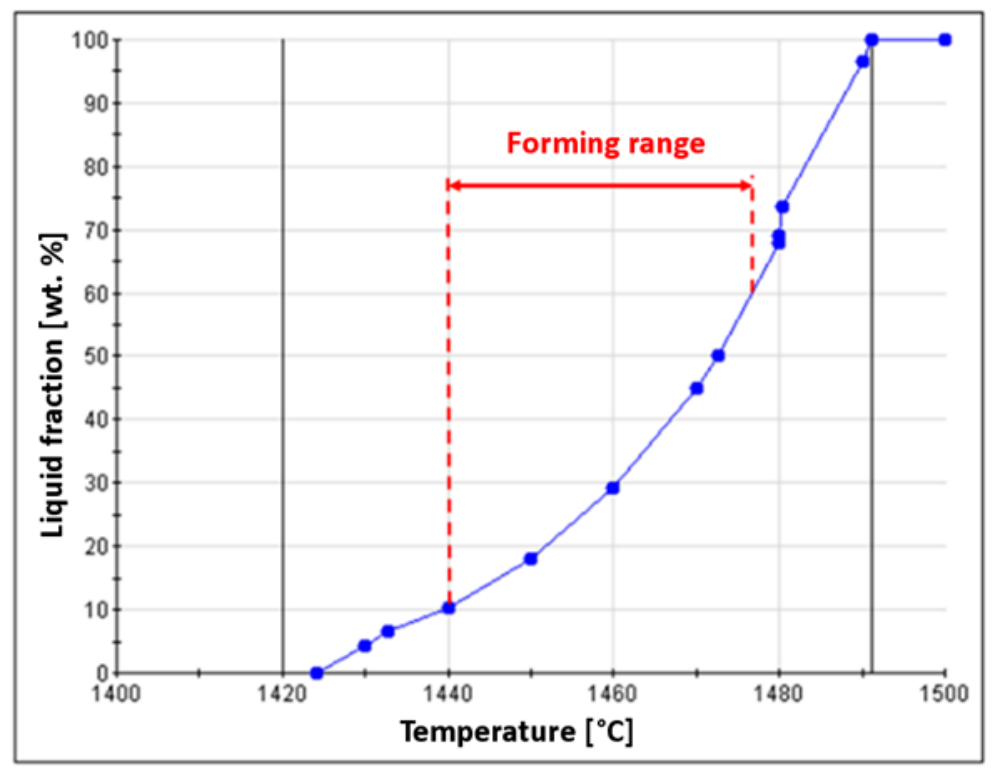

Fig. 1. Calculated forming range

First, the calculated processing temperature had to be verified because the calculated data may differ from the actual characteristics. Based on the calculations, five heating schedules were proposed (Schedule 1 - Schedule 5). Each schedule consisted of controlled heating to a soaking temperature at $25{ }^{\circ} \mathrm{C} / \mathrm{s}$, a 15 -second hold for temperature equalization, and final cooling with water to room temperature. In Schedule 1, the maximum temperature was $1435{ }^{\circ} \mathrm{C}$. The temperature in each subsequent schedule was $5{ }^{\circ} \mathrm{C}$ higher, up to $1455^{\circ} \mathrm{C}$.

Then, schedules for the processing in the die were designed. The equipment uses cross-extrusion of feedstock heated directly in the die. The advantage of this route lies in that the feedstock that has been heated to the semi-solid region need not be handled or transferred. The feedstock was a cylinder of $6 \mathrm{~mm}$ diameter and $46 \mathrm{~mm}$ height. The cavity for the feedstock to be injected into had a length of $20 \mathrm{~mm}$ and a $5 \times 1.9 \mathrm{~mm}$ cross-section. The purpose of using this route was to determine suitable process parameters, achieve complete filling of the cavity and obtain a product with a good surface quality. The feedstock was heated in a controlled manner to $1455^{\circ} \mathrm{C}$, held for approximately 10 seconds and then formed. The heating time was $61 \mathrm{~s}$. The deformation which took about 0.3 seconds was followed by rapid solidification enhanced by the product's contact with the metal cavity surface. The initial cooling rate was approximately $300{ }^{\circ} \mathrm{C} / \mathrm{s}$. By the time the product temperature reached $600{ }^{\circ} \mathrm{C}$, the die wall has become warmer by absorbing the heat and the cooling rate decreased (Fig. 2).

The next stage of the experiment focused on simulating the forming process and on exploring the concurrent microstructural evolution. In the course of the mini-thixoforming sequence, the semi-solid material comes into contact with the die wall and solidifies rapidly, while the die wall removes the heat from the product. The resulting product microstructure consists of pure martensite. If the die had been pre-heated, the cooling rate would be slower and bainite may be obtained in the product. Alternatively, the martensitic structure may be produced and immediately tempered by the residual heat. This would take place right in the cavity without the need for subsequent treatment of the product. In the first step, it was necessary to determine suitable cooling parameters, so that the schedule applied to the specimen in the die was equivalent to the one used for specimens with the gauge length of $16 \mathrm{~mm}$ and a diameter of $8 \mathrm{~mm}$.

After that, the workpiece cooling process to be used for the specimen in the die had to be simulated. For this purpose, two additional schedules were carried out. They comprised heating to $1455^{\circ} \mathrm{C}$ and holding for 10 seconds. The first one (Schedule 8) involved rapid cooling in 20 seconds, whereas the cooling rate in the other (Schedule 9) was very slow (with a cooling time of approximately 3362 seconds). On the basis of CCT diagrams for every particular initial condition of the material, additional heat treatment schedules were proposed. The additional three schedules (Schedule 10 - Schedule 12) were similar to the two schedules described above, but their cooling sequences were altered. The purpose of using these three schedules was to vary temperatures and cooling rates to obtain different microstructures. The specimens were heated to $1455^{\circ} \mathrm{C}$, held for 5 seconds and then cooled in an interrupted quenching sequence. First, they were cooled at a high rate to one of the prescribed temperatures of $700{ }^{\circ} \mathrm{C}, 600{ }^{\circ} \mathrm{C}$ and $400{ }^{\circ} \mathrm{C}$, and then slowly cooled to approximately $100^{\circ} \mathrm{C}$. Consequently, various final microstructures have been obtained (Fig. 3). 


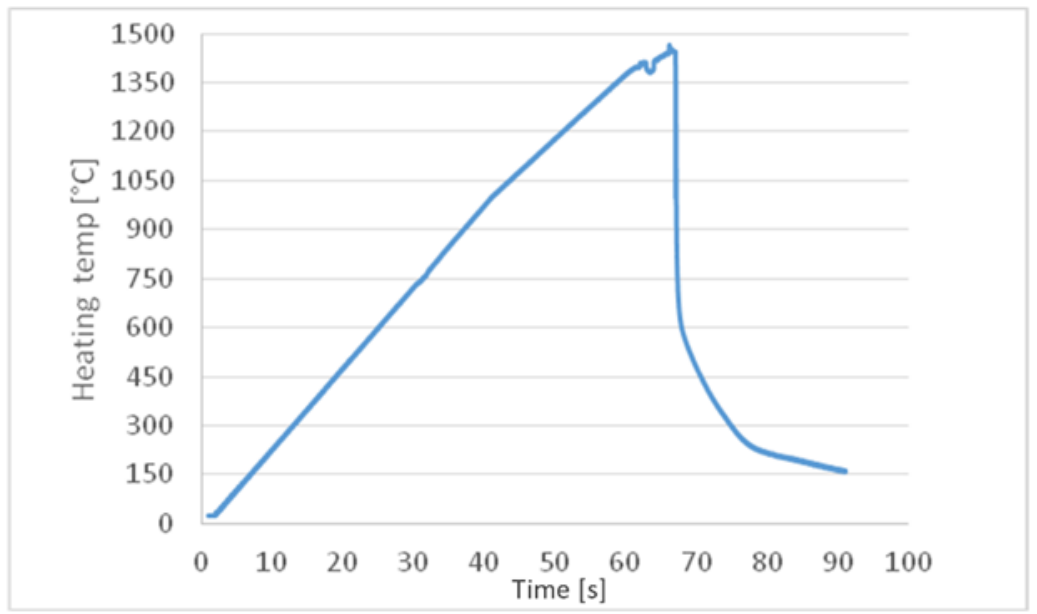

Fig. 2. Processing schedule in die cavity

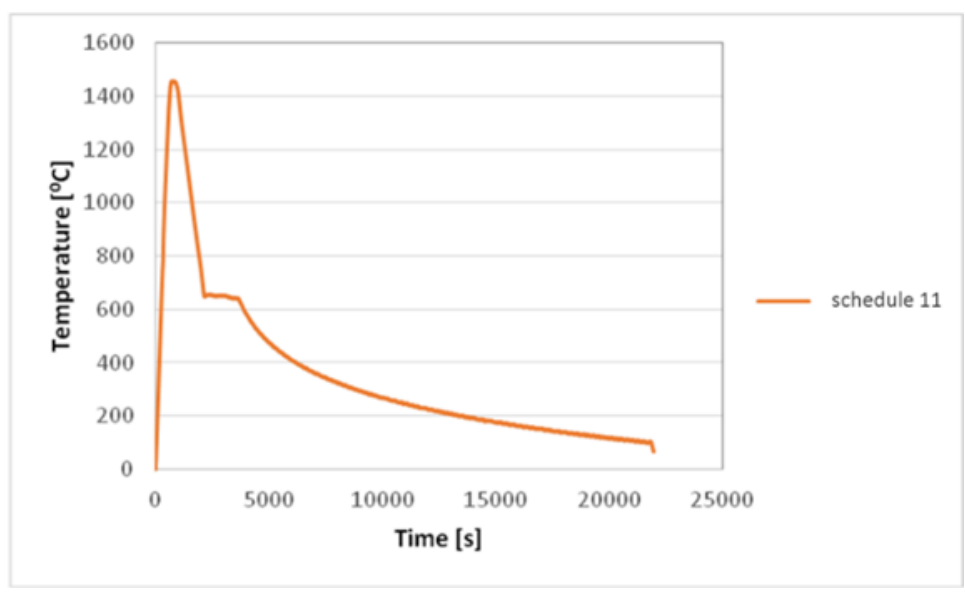

Fig. 3. Temperature vs. time curve for cooling to $600{ }^{\circ} \mathrm{C}$

\section{Results and discussion}

By means of the first five schedules (Schedule 1 - Schedule 5), the effect of temperature on the liquid fraction was mapped. This effect was studied by etching the specimens for identification of prior austenite grain. It was found that up to $1445{ }^{\circ} \mathrm{C}$, the liquid fraction is too small for the required properties to be achieved. The impact of temperature upon the processing is not negligible. Upon all these schedules, the product microstructure was mixed and contained martensite (Figs. 4 and 5). The hardness was approximately 550 HV10.

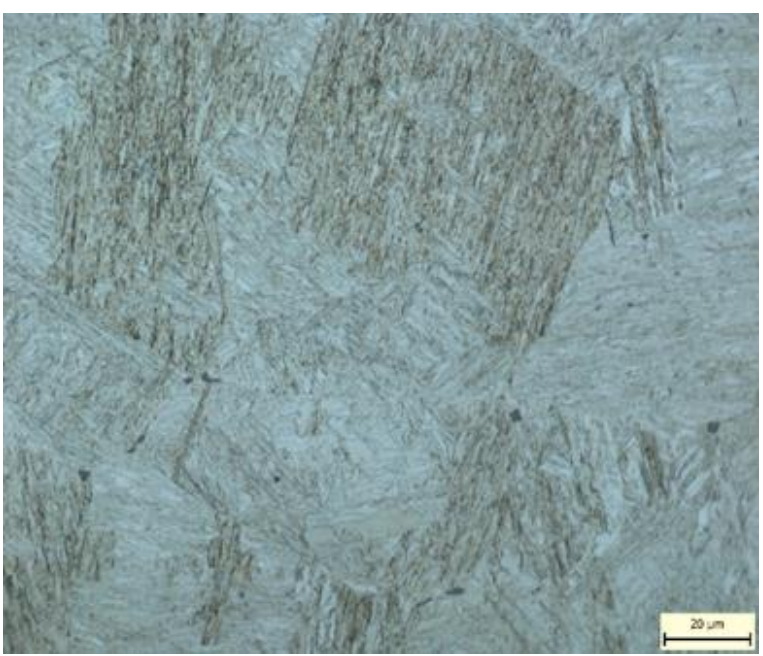

Fig. 4. Schedule 2: $1435{ }^{\circ} \mathrm{C}$

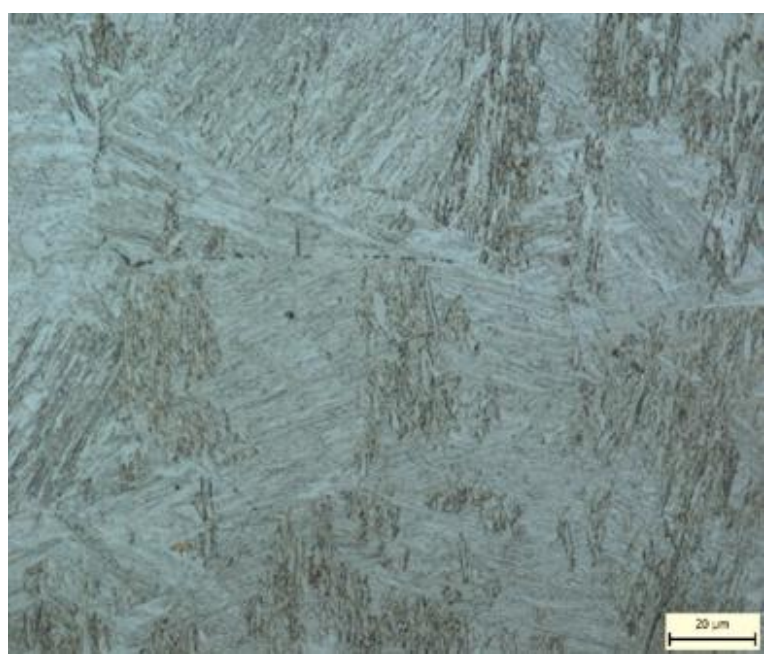

Fig. 5. Schedule 7: $1455^{\circ} \mathrm{C}$ 
In schedules 8 and 9 , the feedstock was heated to $1455{ }^{\circ} \mathrm{C}$. Schedule 8 involved 20 -second cooling. The product of Schedule 8 contained martensite-bainite microstructure (Fig. 6). The product of Schedule 9 consisted of ferrite, pearlite and non-uniformly distributed bainite (Fig. 7).

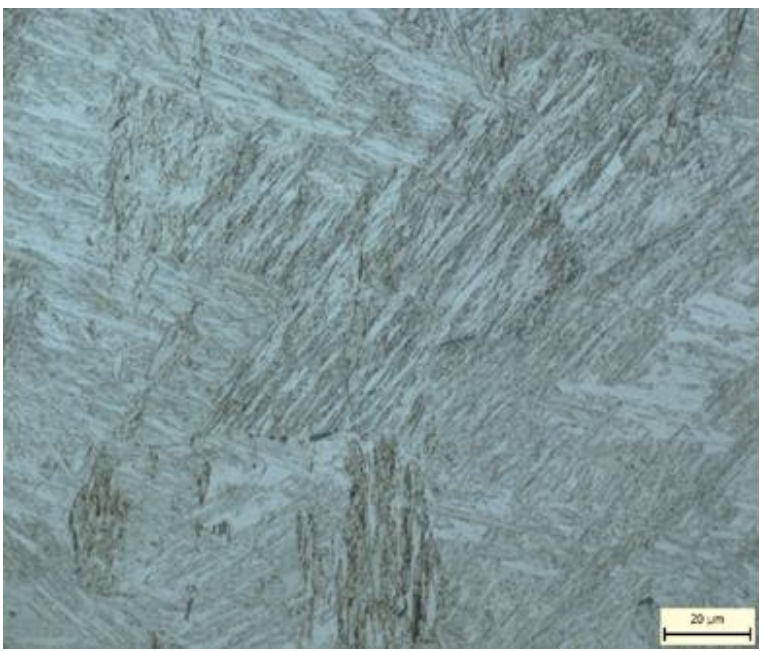

Fig. 6. $1455^{\circ} \mathrm{C}$; cooling time $20 \mathrm{~s}$; martensite-bainite microstructure

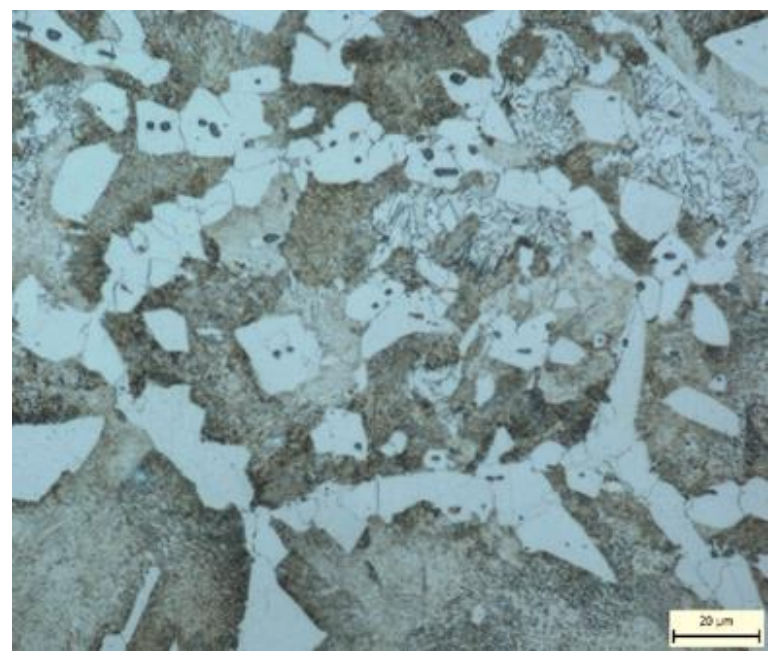

Fig. 7. $1455^{\circ} \mathrm{C}$; very slow cooling; ferrite-pearlite microstructure
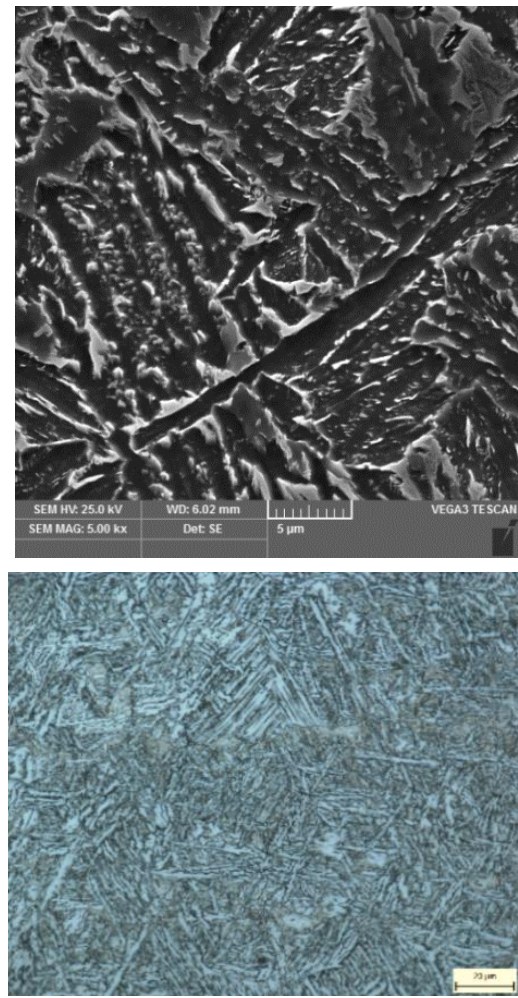

Schedule 10: $600{ }^{\circ} \mathrm{C}$
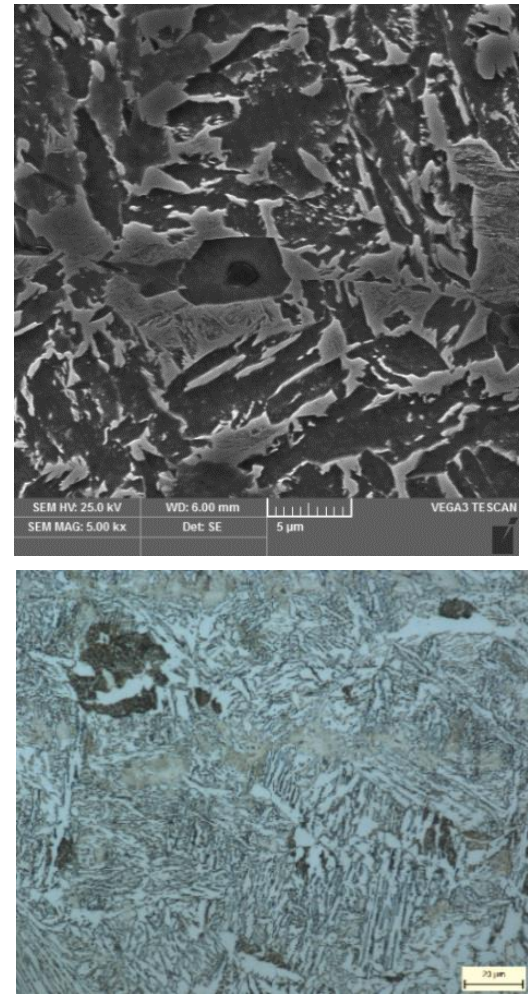

Schedule $11: 700{ }^{\circ} \mathrm{C}$
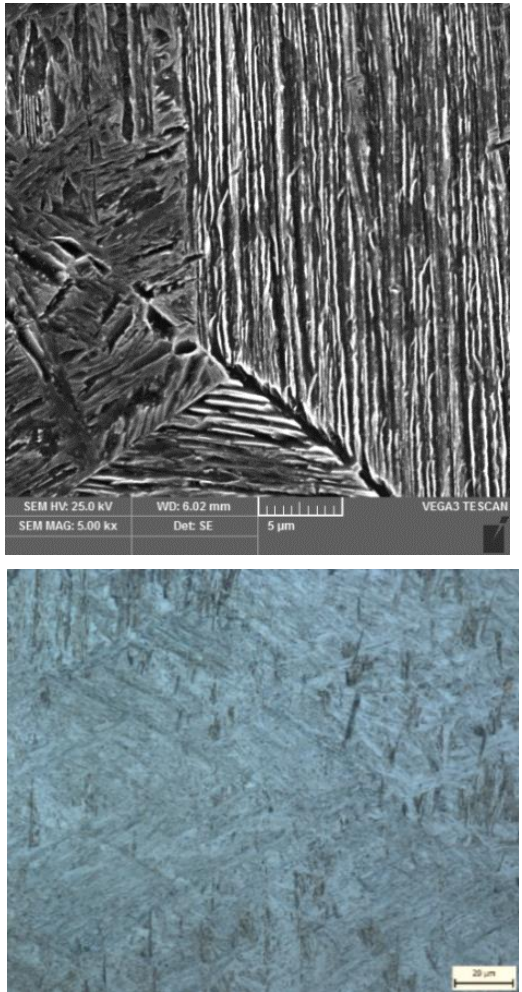

Schedule $12: 400{ }^{\circ} \mathrm{C}$

Fig. 8. Microstructures obtained upon cooling to various intermediate temperatures

The purpose of using the altered cooling rates in Schedules 10 - 12 was to obtain larger fractions of bainite and thus improve the mechanical properties of the product. The cooling first took place at a high rate to a pre-defined temperature and was followed by slow cooling below that temperature. The resulting microstructures were then compared with respect to this intermediate temperature (Fig. 8). The best microstructure, consisting predominantly of bainite, was obtained by cooling to $600{ }^{\circ} \mathrm{C}$. Its mechanical properties are better than those of martensite.

The schedule involving the temperature of $1455^{\circ} \mathrm{C}$, forming in the die, and cooling at a high rate led to mixed martensite-bainite microstructure (Fig. 9). 


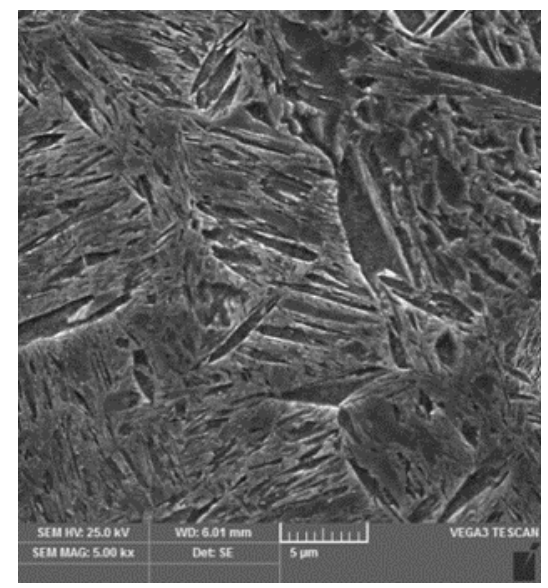

Fig. 9. Mini-thixoformed microstructure of 30MnVS6 steel

\section{Conclusions}

The experimental programme was focused on finding suitable forming parameters for 30MnVS6 low-alloy medium-carbon steel and on exploring individual effects which play a role in the microstructural evolution during semisolid processing. Tentative processing parameter values were found by calculation using JMatPro software [9]. In a series of experiments, the suitable processing range of $1450-1455^{\circ} \mathrm{C}$ was identified. The expectation that processing and rapid solidification would lead to a predominantly martensitic microstructure with a hardness of more than $550 \mathrm{HV}$ was corroborated by metallographic analysis. For optimum mechanical properties of the products, however, the final microstructure should contain mainly bainite. In order to achieve that, controlled cooling schedules with holds at various temperatures, $400{ }^{\circ} \mathrm{C}, 600{ }^{\circ} \mathrm{C}$ and $700{ }^{\circ} \mathrm{C}$, were proposed on the basis of CCT diagrams to simulate forming in a pre-heated die. Although slower cooling rates were applied in the experiment, pure bainite has not been obtained. The best results were attained with the holding temperature of $600{ }^{\circ} \mathrm{C}$ where bainite prevailed in the final microstructure. Corresponding to this finding was the hardness of $300 \mathrm{HV}$. At the next stage of the experiment, the feedstock was processed by mini-thixoforming in a closed cavity of a die. Using a forming temperature of $1455{ }^{\circ} \mathrm{C}$, a mixed martensite-bainite microstructure was obtained. The experiment showed that mini-thixoforming can be used for processing low-alloy medium-carbon 30MnVS6 steel which possesses a narrow freezing range. By this route, it is possible to obtain a bainite-martensite microstructure, as opposed to the typical semi-solid-processed microstructures in steels, i.e. those with globular particles and a carbide network. This altered microstructure can be transformed by subsequent heat treatment into other types of microstructures, depending on required mechanical properties, which will be the subject of future research.

\section{Acknowledgements}

This paper includes results achieve under the project no. LO1502 "Development of Regional Technological Institute" and no. SGS-2013-028 "Support of Students' Scientific Activities in the Area of Material Engineering". The projects are funded by the Ministry of Education of the Czech Republic from specific resources of the state budget for research and development.

\section{References}

[1] M. C. Flemings, Behavior of metal alloys in the semisolid state [J]. Metall Trans A, 1991, 22: 957-981.

[2] G. Hirt and R. Kopp R Thixoforming: Semi-solid Metal Processing. Edited , pp 1 - 27, Copyright 2009 WILEYVCH Verlag GmbH \& Co. KGaA, Weinheim ISBN: 978-3-527-3220 4-6.

[3] W. Püttgen, W. Bleck, G. Hirt, H. Shimahara, Thixoforming of Steels - A Status Report, Advanced Engineering Materiale, 9, No. 4 (2007), 234- 245.

[4] B. Mašek, F. Vančura, D. Aišman, H. Jirková, Minithixoforming of high chromium tool steel X210Cr12 with various initial states in: Annals of DAAAM for 2011 \& Proceedings of the 22nd International DAAAM Symposium, ISBN 978-3-901509-83-4, ISSN 1726-9679, pp 1307-1308, Editor Katalinic B., Published by DAAAM International, Vienna, Austria 2011

[5] D. Aišman, B. Mašek, Š. Jeníček, Unvoncentional Microstructures in Tool Steel Obtained by Semi-Solid Processing and Subsequement Heat Treatment. In:S2P 2014. Pfaffikon, Schwitzerland: Trans Tech Publications Ltd., 2015. s. 235-240. ISBN: 978-3-03835-220-4 , ISSN: 1012-0394

[6] B. Mašek, D. Aišman, H. Jirková, Effect of the Initial Microstructure on the Properties of Low-Alloyed Steel Upon Mini-thixoforming. In: MATERIALI IN TECHNOLOGIJE, 2014, roč. 5, č. 48, s. 719-723. ISSN: 15802949 
[7] F. Vančura, I. Vorel, V. Pileček, B. Mašek, Material Technological Modeling of Thermomechanical Processing of Die Forging of Microalloyed Steel, Kovárenství, 2015, ISSN 1213-9289.

[8] W. H. Bauer and E. A.Collins, in F. R. Eirich (Ed.), Rheology: Theory and Applications, Vol.4, Academic Press, New York, 1967, ch. 8.

[9] A. Wolf, J. Baur, G. C. Gullo, Thixoforging, Available from: http://www.cctbw.de/veroeffentlichung_pdf/WoBa\%20Massiv01\%20english.pdf.

[10] JMatPro, The Java-based Materials Property Simulation Package, Version 6.1, Sente Software Ltd., Surrey Technology Center, UK

[11] A. Ronešová, B. Mašek, H. Staňková, C. Štádler, Patent CZ No. 299758 - Method of handling and its shaping at a temperature between solid and liquid, (3 Oct. 2008).

[12] B. Mašek, H. Jirková, L. Kučerová, A. Ronešová, J. Malina, Material-Technological Modelling of Real Thin Sheet Rolling Process., METAL 2011., 20th Anniversary International Conference on Metallurgy and Materials, 2011, pp. 216-220. Edit. TANGER Ltd., ASM Int, Mat Informat Soc; CSNMT; VSB-TU. ISBN 978-80-87294-24-6. 